\title{
Teachers' Responses to an Investigative Mathematics Syllabus: Their Goals and Practices
}

\author{
Stephen Norton, Campbell J. McRobbie, and Tom J. Cooper \\ Queensland University of Technology
}

\begin{abstract}
Despite attempts to encourage teachers to adopt investigative teaching behaviours there is strong evidence of the resilience of teacher-centred school mathematics teaching. This study uses interpretive research methods to explore teachers practices and relate these to their goals. Analysis of case studies indicates that syllabus documents have influenced teachers choices of teaching strategies, Most teachers had calculation-based goals for less able students and conceptual goals for more able students. Three distinct teaching strategies were identified and described. The relationships between teachers' goals, beliefs, and practices can guide the construction of teacher programmes that focus on student construction of knowledge.
\end{abstract}

In 1989, the National Council for Teachers of Mathematics (NCTM) introduced its new standards (NCTM, 1989), a reform curriculum that was imitated by later Australian curricula. The NCTM document emphasised the importance of "doing" mathematics rather than "knowing that" (p. 6), stressed that mathematical knowledge "should grow out of problem situations; and second, learning occurs through active as well as passive involvement with mathematics" (p. 8), and criticised traditional teaching practices because their "emphasis on practise in manipulating expressions and practising algorithms as a precursor to solving problems ignore the fact that knowledge often emerges from the problems" (p. 8). Further, the document recommended that teachers become facilitators of learning rather than imparters of information.

This emphasis on problem solving and facilitation continued into the second NCTM statement on standards (NCTM, 2000), where teachers were encouraged to allow their students to "make, refine, and explore" and to become "flexible and resourceful problem solvers" (p. 3). The emphasis was echoed by the national statement developed by the Australian Education Council (AEC), in both rationale and recommendations about teaching strategies (AEC, 1990), and the 2000 draft of the Queensland P-10 mathematics syllabus (Queensland Schools Curriculum Council [QSCC], 2000). The AEC document recommended developing students' capacity to use mathematics in "dealing with non-routine mathematical problems and unfamiliar situations ... both individually and collaboratively" (p. 12) and allowing learners to construct their own meanings from, and for, the ideas, objects and events which they experience" (p. 16). It criticised traditional teaching practices and stated that "mathematics develops through the interaction of communities of people" (p. 13). The QSCC document reflects the strong influence of the NCTM (1989). Similar to the NCTM and AEC documents, the QSCC document emphasised the common themes of learner focus and active engagement, often in a social setting.

In this paper, the approaches to mathematics teaching recommended by NCTM and AEC are called investigative. The essence of investigative learning is contained in the recommendations of three mathematics curriculum documents: (a) 
Curriculum Council (1998) that stated that "mathematical learning is most successful when students actively engage in making sense of new information and ideas" (p. 1); (b) Australian Association of Mathematics Teachers (AAMT) Inc. (1996) that argued for "investigating mathematical processes situated within meaningful contexts" (often derived from real-world data) (p. 4); and (c) Anderson (1994) that concluded "effective learning and teaching requires active construction of meaning" (p. 1).

Terms other than investigative have been used in other documents for the problem solving and facilitative approach described above. For example, Senior Secondary Assessment Board of South Australia (2000) used the term "problemsolving approach", recommending that students "construct mathematical models, typically by establishing functional relationships, and use them to solve problems" (p. 5), while Carroll (1997) and Senger (1999) used the terms "Everyday Mathematics" and "reform curricula", respectively. A number of terms have been used to describe investigative teaching with its emphasis on problem solving, reasoning, communication, use of manipulative material, group work, and facilitation, where teachers see themselves as guides, listeners, and observers rather than authorities and answer givers.

Curriculum documents that are essentially investigative reflect theories of learning consistent with major elements of social constructivist theory. They acknowledge the importance of students actively constructing their own knowledge from the environment through interaction with physical reality and through social interaction with peers and teachers (Cobb, Yackel, \& Wood, 1992; Vygotsky, 1987). This social constructivist stance, that acknowledges the importance of both social and personal elements in learning, is referred to in this paper by the term constructivist.

In the USA, there has been resistance to the investigative approach and opponents have formed a movement called Mathematically Correct. Members of Mathematically Correct reject the idea that student construction of knowledge ought to be central to mathematics learning and believe that investigative approaches downgrade basic skills, partly because the time taken to "discover" means less material can be covered and partly because "memorisation" has not been developed and utilised (Allen, 1998). They acknowledge that mathematics includes some discovery and modelling of the reality of the world, but oppose student discovery. They recommend a return to teacher exposition or "direct instruction" with an emphasis on basic skills and practice, predominantly by students working individually (Allen, 1998). They believe that mathematical concepts and understandings are better and more efficiently developed through teacher-centred rather than learner-centred pedagogy.

In Australia, there has been similar resistance to attempts by curricula writers to persuade teachers to adopt investigative approaches to teaching (McDonald \& Ingvarson, 1995; McRobbie \& Tobin, 1995). This is particularly the case in low socioeconomic urban schools where teachers tend to adopt directive and authoritarian pedagogies (Perry, Howard, \& Tracey, 1999).

Teachers' classroom practices are strongly connected to whether their teaching orientation is calculational or conceptual (Thompson, Phillip, Thompson, \& Boyd, 1994). They argue that a calculational orientation is "driven 
by a fundamental image of mathematics as the application of calculations and procedures for deriving numerical results" (p. 86) and is strongly associated with teaching practices that focus on procedures for "getting answers", usually numerical in nature. It is a common orientation in secondary mathematics teaching (Crawford, 1996; Gregg, 1995; Perry et al., 1999), is related to teaching behaviours described as content-focused with an emphasis on performance (Kuhs \& Ball, 1986) and instrumental (Skemp, 1978), and is linked to transmission images of learning (Atweh \& Cooper, 1995; Perry et al., 1999). By contrast, a conceptual orientation is associated with teaching behaviours that "focus students' attention away from the thoughtless application of procedures and towards a rich conception of situations, ideas, and relationships among ideas" (Thompson et al., 1994, p. 86), that is, that focus on solving problems by working from a deep understanding of the mathematics underlying the problems. A conceptual orientation is consistent with the Kuhs and Ball's (1986) category of teaching behaviour described as content-focused with an emphasis on understanding and with Perry et al.'s (1999) child-centred approach to teaching.

\section{Purpose}

This paper reports on a study to explore how Queensland secondary mathematics teachers are responding to a syllabus that encourages investigative teaching and learning. It investigates reasons why teachers may resist such syllabi. The specific research objectives of this study are:

- to investigate how teachers are responding in their teaching practice to the recommendations of this syllabus; and

- to relate teachers' practices to interpretations of the reform Syllabus and their goals for students.

\section{The Syllabus}

In this study the focus is upon the Senior Mathematics B syllabus (BSSSS, 1992) as an example of an investigative syllabus. Mathematics B is an academic but not specialist course and was developed for students with aspirations to study a tertiary course that has a mathematics component (there are less academic mathematics options for students without these aspirations). It was designed to be investigative in its approach to pedagogy, as is stated in its rationale:

Mathematics education must recognise the dynamic nature of mathematics and encourage an approach to its study through problem solving and applications in life related contexts. (p. 1$)$

In support of this rationale, the learning experiences in Mathematics $\mathrm{B}$ also emphasised an investigative approach. For example, for the topic area of applied geometry, the recommended teaching approach was based on "experiences which involve life-related applications of mathematics, including both real and simulated situations, use of instruments, and the opportunity for problem solving" (p. 11) and contained many recommendations to "design," "investigate", or "model" practical problems (pp. 12-13).

However, the assessment procedures for Mathematics B tended to work 
against an investigative approach. The importance of testing procedures in influencing teachers' behaviours has been well documented (Barnes, Clark, \& Stephens, 1996; Gregg, 1995). Students are awarded one of five exit levels of achievement. They are assessed against three criteria: communication, "clear and concise use of appropriate terminology and ap propriate forms of presentation, while consistently adhering to the conventions of language and mathematics" (BSSSS, 1992, p. 41); techniques, involving the recall of rules and procedures, use of instruments and the application of these in familiar situations: and applications involving applying mathematics in unfamiliar situations. They are expected to consistently perform at high levels in all criteria in order to be awarded the top achievement level. However, in order to achieve a middle level, students need to demonstrate "some knowledge of mathematical techniques" and be "generally accurate and proficient when applying them to familiar situations" (BSSSS, 1992, p. 42); and when they only "rarely provided solutions in unfamiliar situations" (BSSSS, 1992, p. 42). Thus, it is possible for students to have the middle level of Sound Achievement in Mathematics B with only procedural knowledge of techniques and without knowledge of applications. Students with Sound Achievement may be without conceptual understanding of mathematics because, as Tall and Thomas (1991) argued, students can carry out computations without conceptual understanding but success on unfamiliar problems requires it. Moderation of Mathematics B does not seem to have taken into account that the criteria for Sound Achievement do not require the understandings that are at the basis of an investigative approach to teaching mathematics.

\section{Method}

The study was a series of embedded qualitative educational case studies (Stenhouse, 1990) involving an interpretive and constructivist approach (Denzin \& Lincoln, 1994). In particular, the study was interpretive in that the goal was to understand the meaning of a social phenomena while giving recognition to the subjective nature of observation, and it was constructivist in that findings were allowed to emerge from the data in an hermeneutic cycle which took account of perspective in relation to knowledge and recognised that "truth" is created by the mind (Schwandt, 1994). The researcher employed a wide range of interconnecting research techniques.

\section{Subjects and Contexts}

The study was carried out in two Brisbane suburban schools (denoted by pseudonyms). The first school, Forest View, was a large (1400 students) coeducational government school located in a middle class suburb. The second school, Hill View, was a mid-sized (650 students) girls Catholic school also located in a middle class suburb. Forest View and Hill View were both regarded by the district Mathematics B panel review members as innovative schools with high teaching standards. Further, the researcher had developed a close rapport and mutual trust with several of the staff in each school. This was critical in obtaining rich data (Fontana \& Frey, 1994). 
Six of the most senior mathematics teachers at Forest View and three at Hill View became the subjects of the study. These teachers were seen as experienced and competent teachers by other school staff. Present and previous computer and mathematics staff coordinators at both schools confirmed these teachers as influential in the teaching of mathematics in their schools. They were the writers of the work programmes and internal assessment tasks that stipulated (a) which concepts would be taught and when, and (b) which textbooks and other resources would be selected for the other teachers to use. The importance of textbook selection in influencing teaching practice has been recognised previously (Crawford, 1996; Neyland, 1996). In short, these teachers became participants because they had considerable influence on how mathematics was taught in each school.

\section{Data Sources}

Data were collected using a teacher questionnaire, classroom observations (using field notes), interviews (using audio recordings), and from students' examinations and mark allocations. The questionnaire was administered first and designed to collect data on demographics and beliefs about mathematics and teaching mathematics. Following the emergent nature of the methodology, the observations and interviews were designed taking into account the results of the survey. The questionnaire contained 31 statements to which teachers responded on a five-point Likert scale. The work of Ernest $(1989,1991,1996)$ and Cobb (1988, 1989) was used as a framework upon which to design questions about the nature of mathematics.

The interview instrument was designed to probe for beliefs about the nature of mathematics teaching by seeking to identify what aspects of mathematics were considered important. Items that reflected strong beliefs in the importance of performing procedures in mathematics study, included "There is considerable merit in getting back to basics." A more conceptual focus was reflected by items such as "Basic skills are less important than the ability to transfer problem solving strategies." The work of Kuhs and Ball (1986) provided a theoretical framework for the structuring of questions probing teachers' beliefs about the nature of teaching mathematics. For example, agreement with the statement "Listening to and thinking about my explanations forms the basis of most of my students' learning" was considered to indicate a teacher centred approach. By contrast, agreement to statements such as "I sit students in groups to facilitate discussion" and "It is important for students to do solutions in their own way," were considered to indicate a learner-focused pedagogy based upon principles of constructivism.

\section{Procedure}

The data explored in this study were collected at the two schools over a twelve-month period in the following four-stage sequence:

- preliminary interviews with the mathematics Heads of Departments (HODs); 
- $\quad$ surveys of most of the mathematics staff in each school;

- purposeful selection of the nine teachers using the responses from the survey, and

- observations of the nine teachers' classes, interviews with them, and collections of students' examinations and mark allocations.

For each of the nine teachers, two to four lesson observations were undertaken. Field notes were taken of the classroom activity, the black board presentations, and the teacher and student interactions, and audio-recordings were made of the teachers' dialogues with their students. These were transcribed.

Up to six interviews of the selected teachers were made before and after the observations. During these interviews, the teachers were asked to explain their reasons for conducting classes in the way that they did. The researcher used the teachers' responses to the survey instrument to probe their beliefs and practices and introduced contrasting and divergent views and images, giving the study a dialectic nature (Guba \& Lincoln, 1989), in order to probe reasons for beliefs and practices. Both direct and indirect questioning was used. For example, the teachers were asked what they thought of the two textbook series, Investigating Change: An Introduction to Calculus for Australian Schools (Barnes, 1991) and Access to Algebra (Lowe, Johnston, Kissane, \& Willis, 1993). The teachers' responses were found to be very revealing of their beliefs. The two text series have many investigative activities that are learner focused and encourage conceptual development through physical activity, discovering patterns and then formalising the mathematics. Many of the activities are embedded in a practical and cultural context. Thus, rejection of these resources was interpreted as a rejection of the pedagogy that underlay them. Kagan (1992) argued that this indirect method of collecting data reduces unintentional cues and the chances of leading the subject. The teachers were also asked to explain the factors that guided their teaching practice of able and less able students, and to comment on the syllabus.

A final interview with each teacher (following the analysis of the data) was conducted in which the major findings were reported for their comment and confirmation as a reasonable interpretation of their beliefs and practices.

\section{Analysis}

Each data collection source was used to inform the subsequent data collection and analysis. The data were analysed using procedures that involved "examining the meanings of peoples' words and actions" (Maykut \& Morehouse, 1994, p. 121). Combining the teachers' responses to the survey instruments and interviews with the classroom observations developed a rich description of each teacher's beliefs and practices. Triangulation was achieved with teachers' reactions to the text resources and the researchers' assertions. The descriptions were analysed for commonalities and three teachers were chosen as being typical of the distinct teaching preferences, goals and beliefs about teaching held among the nine teachers. The results are presented as descriptions of these three teachers followed by summaries and their relation to other similar teachers. 


\section{Results}

The first teacher (pseudonym Eva) was illustrative of a predominantly calculational orientation and her teaching approach has been described as show and te1l, since the dominant teaching behaviour was one of modelling correct application of algorithms. The second teacher (David) illustrated what has been classified as the explain teaching approach. That is, his dominating behaviour was careful explanations of the logic behind mathematical concepts, particularly when teaching able students. The final teacher (Jan) mostly used what has been classified as an investigative teaching approach in her teaching of more able students. David and Jan are not pseudonyms - after member checking, these teachers asked to be referred to by their Christian names.

Prior to considering each of the three selected teachers, the goals and teaching approaches of all the nine teachers are summarised (see Table 1). The table shows that the show and tell, explain and investigative patterns of behaviour were common among the staff in these two schools.

Table 1

Summary of Teachers' Goals and Favoured Pedagogy

\begin{tabular}{lllll}
\hline Teacher & \multicolumn{2}{c}{ Stated Goals for } & \multicolumn{2}{c}{ Pedagogy for } \\
\cline { 2 - 5 } & Able Students & $\begin{array}{l}\text { Less able } \\
\text { Students }\end{array}$ & Able Students & $\begin{array}{l}\text { Less able } \\
\text { Students }\end{array}$ \\
\cline { 2 - 5 } Eva & Conceptual & Conceptual & Show and tell & Show and tell \\
Sasha & Conceptual & Calculational & Show and tell & Show and tell \\
Will & Conceptual & Calculational & Show and tell & Show and tell \\
David & Conceptual & Calculational & Explain & Show and tell \\
Peter & Conceptual & Calculational & Explain & Show and tell \\
Kurt & Conceptual & Calculational & Explain & Show and tell \\
Jan & Conceptual & Calculational & Investigative & Show and tell \\
Mary & Conceptual & Calculational & Investigative & Show and tell \\
Simon & Conceptual & Conceptual & Investigative & Investigative \\
\hline
\end{tabular}

\section{Findings for the Show and Tell Teacher}

Eva was 28 years of age and had taught in her school since she began teaching six years ago. Eva had completed a Bachelor of Science majoring in mathematics and psychology. At the time of the interview, she was teaching junior mathematics (Years 8, 9, \& 10) and Mathematics A (Years 11 \& 12). She had been a member on the Mathematics A panel for one year. Two years prior to the interview, Eva had been made coordinator of junior mathematics. Since this time, the frequency of open-ended student assignments had been reduced from four a semester to one a semester, the use of the problem-solving student centred and activity-based text, Access to Algebra (Lowe et al., 1993), had been reduced, and 
a more traditional text, Mathematics Year 10 for Queensland (Wasley, Manche \& Winter, 1996), had been adopted. Her justification for discontinuing the use of Access to Algebra was that the text was "too laborious for good students and too confusing for students who are slow readers."

Eva had stated that her goal for both able and less able students was to help them understand mathematics concepts, but in her survey and interview responses, she indicated a narrow conception of understanding. For example, in her completion of the survey, she responded in a way that indicated she considered "getting back to the basics" very important. She stated "I think everything is based upon those algorithms ... it is based upon laws and theorems and algorithms." Her beliefs about teaching and learning conformed to the transmission/absorption model. She stated that she liked to "show them and tell them". She described her teaching of trigonometry as follows:

Well with tan I always start, off with SOHCAHTOA .... And from there I'd tell them that before we can even start looking at tan we need to do a bit on right angled triangles. because that's where the principle of SOHCATOA comes from.

She went on to describe how she would clearly tell students what they need to know and how to remember the procedure. It is interesting that Eva describes SOHCAHTOA as a principle. At no stage during Eva's lengthy explanation of her pedagogy did she suggest that students might be required to make their own conclusions about the meaning of SOHCAHTOA.

Eva emphasised individual rather than cooperative student work. She explained:

I put them all in single file, because I've found in the past (that) putting them in groups. putting them in two by twos. just does not work for some reason. I find them more focused when they are seated in single file.

In the classes observed, her students were indeed seated in rows. Student communication was limited to surreptitious whispers. This was not surprising since Eva had stated:

From the moment they meet me. every new class I have. I make it very clear to them what my expectations are. And I have only one simple rule, that is, when I am teaching please do not distract me or anyone around you. I set those rules and make those expectations.

Lesson observation confirmed the strict conformity of the class, suggesting that Eva had commanded their compliance. The lessons observed were very ordered and controlled. Students who were fast in putting their hand up, answered questions without providing explanation of their answers. In the latter part of each lesson, students who finished the question that was placed on the white-board were nominated to come out to the white board and illustrate a portion of their answer. No student explained the complete answer or their reasons for each step in the solution. It appeared that coming out to the white board was a reward for speed in completing the algorithm. In addition, if a student made a mistake she would sit down and another student would have a chance to correct the previous error. At no time were students asked to discuss a mathematical concept or share their ideas with fellow students or work cooperatively. The following dialogue was typical of the sort of explanation, question and answer dialogue that made up most of the lesson. 
[Eva had drawn and labelled a right angle triangle on the white board.]

Eva: OK. girls pens down, looking at the board please. OK. what we are going to do now is by using those preliminary exercises that we have just done. we are actually given a right angle and we have been given side lengths and an angle. And in these examples we have to find out one of the side lengths given the other side length the angle. OK. So let's look at the first one please. We're asked to find the value of $x$. where it's been labelled $x$. what side of the right triangle. which part is it labelling? Which side of the right triangle? Rebecca?

Rebecca: The opposite.

Eva: It is labelling the opposite side. Now we are asked to find $x$, so therefore which of our trig. rules are we going to use to find $x$ in this case? Which trig. rule? Which trig. rule? Jackie?

Jackie: Sine.

Eva: Why are we going to use sine?

Jackie: Because ... (pause since the student was unable to answer).

Eva: So, using the information, right. we have been given the opposite. In this case it's been labelled $x$ centimetres. And we have been given the hypotenuse which has been labelled 20 . We need to substitute the information. Crystal, would you do that please.

Crystal: OK. Sine of an angle equals $x$ over ...(unable to continue).

Eva: OK. How dowe solve for $x$ in this case? How do we solve for $x$ ? Sinead?

Sinead: $\quad x$ over $H$.

Eva: Well done. Will every one calculate please. It will equal 20 times sine 28. Hands up when you have got an answer.

The striking aspect of this discourse is that many students share in the process of carrying out this simple application of an algorithm. However, no student ultimately took responsibility for it. If a student faltered, as in the cases of Crystal and Jackie, they were passed over. A student's lack of knowledge or misconception was not probed in the two lessons analysed. There was substantial evidence that Eva did not embarrass students by confronting them with the inadequacy of their conceptions. Eva's earlier statements on the importance of student self-confidence may have been a rationale for this teaching behaviour.

The main focus of Eva's lessons appeared procedural, even though her class was a top stream Year 10 class. For example, SOHCAHTOA had been written on the white board prior to the girls entering the classroom and even before the sine or cosine concepts were explained. Further, the sine question discussed in the example above was one of several of the same form. The researcher examined two student workbooks and there was no evidence that the meanings behind the SOHCAHTOA rule had been taught. It appeared that in past lessons, as in this lesson, the relationships between angles and side lengths were presented as rules. Thus, this lesson supports Eva's statement to the researcher that "mathematics learning is based upon algorithms".

Perhaps the most illustrative classroom example supporting Eva's claim that she liked to show and tell students how to do mathematics was seen in another of her classes. This class was being taught linear equations and Eva wanted to show them that the gradients of perpendicular lines had negative reciprocal gradients. On the white board was sketched the lines $y=2 x-1$ and $y=-1 / 2 x+1$, which were labelled. The students had just spent about 15 minutes revising the gradient and y intercept concepts and had been shown that parallel lines had the same gradient. The students had been asked to look for a relationship between the gradients of the two lines. They had described the gradient in terms of 
negative and positive gradients and described them in terms of steepness of slope, but this was not what Eva wanted.

Eva: No, no, no, is anyone going to say that they are perpendicular lines? All right so they're perpendicular lines. now what do you think would make them perpendicular? The fact that I've drawn in those little boxes there? OK, pretend that I forgot to draw the boxes in to make it more obvious to you. What do you think actually makes graph three $(y=2 x-1)$ perpendicular to graph one $(y=-1 / 2 x+1)$. Just think of the equation or gradient or $y$ intercept, do a little comparison just the information that's there. Kristen

Kristen: Their gradients are opposite.

Eva: Their gradients are opposite. not so much opposite ... yeah go on.

Sally: Inverted of ...

Eva: What's another word that we can actually use for this idea of inverted? One gradient is positive what's the other?

Toni: Negative

Eva: So put all of that new found knowledge together. One gradient is the negative reciprocal. The gradient for graph three is the negative reciprocal of the gradient of graph one. The gradient of graph three is negative a half and the gradient of graph one is two.

By placing the square at the point of intersection of the two lines and drawing students' attention to it, Eva was denying them the opportunity to determine that the two lines were perpendicular. In the end, she told them that the perpendicular lines would have negative reciprocal gradients of each other. This teaching behaviour has been described as "Topaze"-like (Brousseau, 1984) in that the students are asked explicit questions but the teacher takes charge of the main part of the work to the extent that the learning situation is emptied of cognitive content. Lesh and Kelly (1997) described similar teaching behaviours as "bug repair" tutoring behaviour typical of novice tutors, that is, the teacher focuses on guiding students along paths in which errors are avoided.

Eva seemed somewhat unaware of the show and tell nature of her teaching. For example, in the member checking, when the researcher asked Eva to confirm the following assertion, she did not directly answer the question but honed in on one aspect she considered important:

Res.: In teaching in secondary school. you are concerned that students understand the rules and know how to apply them. Thus. your teaching is dominated by teacher explanation and modelling (of solutions and procedures). Students need to attend carefully and be able to follow your demonstrations.

Eva: $\quad .$. well in the sense that I really believe that the foundations have to be there and I demonstrate very clearly. and it has to be taught.

Clearly, Eva believed that teaching strategies based upon direct instruction were a crucial component of her teaching. However, she did not reinforce the "dominate" part of the assertion. This is also evident in her statement about student discussion:

It [discussion] is very important in terms of discovery. If you give them a task and they try to work together to nut it out and to verbally express or explain things to others, that is very important. I try to do quite a bit of that within each lesson, even if it is a minute or two. I would say to the students explain that to me. which means they're explaining to the whole class.

Neither complete explanations nor student discussion were ever observed in any of her lessons. 
Eva did not appear to fully appreciate the distinctions between calculational and conceptual goals. Evidence to support this was observed in her marking of student examinations where she often did not give part marks for answers (both junior mathematics and senior mathematics). That is, she gave zero to students who made a calculational error in the beginning of a three-mark question even if subsequent processes and calculations were correct.

In terms of assessment, Eva was very aware of the importance of examinations in motivating students. She used statements such as, "If you can do this question you will do well on the exam." She described her role as one of building confidence and "helping them to learn and understand the rules of mathematics." Classroom observations, and her descriptions of her teaching and of her goals, created an image of a caring teacher who would help students to do well on examinations, particularly those that emphasised the "basics." An examination of the school's assessment items confirmed that their assessment was dominated by "technique" questions. Eva's rejection of the investigative resources and her reduction of the quantity of investigative assessment required in the junior (Years 8-10) work program support the conclusion that she saw merit in emphasising "the basics (which) you get by clear explanation in the classroom" in assessment as well as teaching.

Finally, Eva appeared not to distinguish between able and less able students in describing her goals and in her teaching. She claimed the same for all students; to teach understanding by emphasising the rules and algorithms that were the foundations of mathematics. She may have believed she had conceptual goals for all students, but observations of her classes supplied no support for a conceptual approach to teaching.

\section{Summary and Relations to Other Show and Tell Teachers}

In this study, three teachers (Eva, Will and Sasha - see Table 1) were found to employ predominantly show and tell behaviours in their teaching of both able and less able students. In observations of their classes, student learning appeared to be by imitation; the teachers demonstrated some questions and the students imitated the teachers' behaviour and performance on similar questions. Being able to apply technique and procedure on closed book examinations was the major goal that was articulated by each of these teachers.

These teachers opted not to use the resources that were dominated by investigative approaches. Their explanations included "too slow ... it takes too long ... it is a female approach to it", "for good students it's so laborious ... for the slow readers the questions just confuse them", and not sure "they would be as efficient". Their comments indicated that rejection of or reluctance to use investigative texts was strongly related to perceptions of how long it would take to cover the content material, which has wider implications for textbook choice considering teachers' perceptions about the crowded nature of the syllabus.

Although Will and Sasha demonstrated teaching strategies that had much in common with those employed by Eva, they did articulate different goals for able and less able students. That is, although they stated that "bright" students could be "taught to understand the logical thinking behind geometry or algebra", 
they believed that less able students had "to be drilled in the skills." Thus, their interview responses appeared to indicate calculational goals for less able students and conceptual goals of more able students.

However, in all three teachers' lessons, little difference was noted in their teaching approaches for the two ability groups. Classroom observations of all three teachers revealed that show and tell teaching approaches were regularly used with all students and included the following behaviours: seating students in rows or individually, short wait time, use of questions to maintain discipline, use of extrinsic motivational techniques such as expectations of better paid jobs, readily reducing the cognitive load, rarely asking students to justify their answers, teaching from the front of the room, preferring to use texts that contained many exercises, and rarely using diagrammatic models. In all the classes observed this teaching behaviour resulted in orderly compliant student behaviour.

\section{Findings for the "Explain" Teacher}

David was a 43-year-old male who had been teaching mathematics for 21 years. He was highly qualified with a Bachelor of Economics, Masters in Regional Science Degree, Graduate Diploma in Teaching and a Graduate Diploma in Education (Computer Education). He was an Advanced Skills Teacher and was the teacher charged with representing the school on the Mathematics $A$ regional panel. He also taught Mathematics B.

David explained that he had two distinct goals for his students. He tried to help his better students understand mathematics concepts. This was expressed in his comments about liking "to pursue higher objectives" after they had developed "a solid understanding of the basics". However, he had more limited goals for his less able students. David stated that he wanted them to pass skills-based examinations and "not get ripped off for their change." As he explained:

I think with the lower level groupings we get you've either got to make a decision as

to ... well ... you've got to see what your objective is. And your objective. I think is

to get them through the examination. That's the thing they are interested in. That's

the thing their parents are interested in.

Typically David began lessons with arithmetic questions to revise basic skills. This was usually followed by modelling procedures and subtly varied subsequent questions. He encouraged estimation and student discussion during bookwork activities, and gave students some autonomy in deciding what activities they could do and how much time they could spend on them. In the observed lessons, he spent most of the time trying to lead students to an understanding of why the procedure worked. He spent more time than Eva with individual students and tailored his questioning to correct specific misconceptions. He based his teaching on reasonably sophisticated questioning skills and analysis of students' misconceptions.

The dialogue below illustrates the assertion that David's pedagogy was based on explanations and shows how he explained concepts to students. In this lesson, the Year 10 students were studying discounts and were asked to find the original price if the discount was given as a percentage and in dollar terms. 
David had modelled a problem on the board and had asked students to complete similar examples from their textbook.

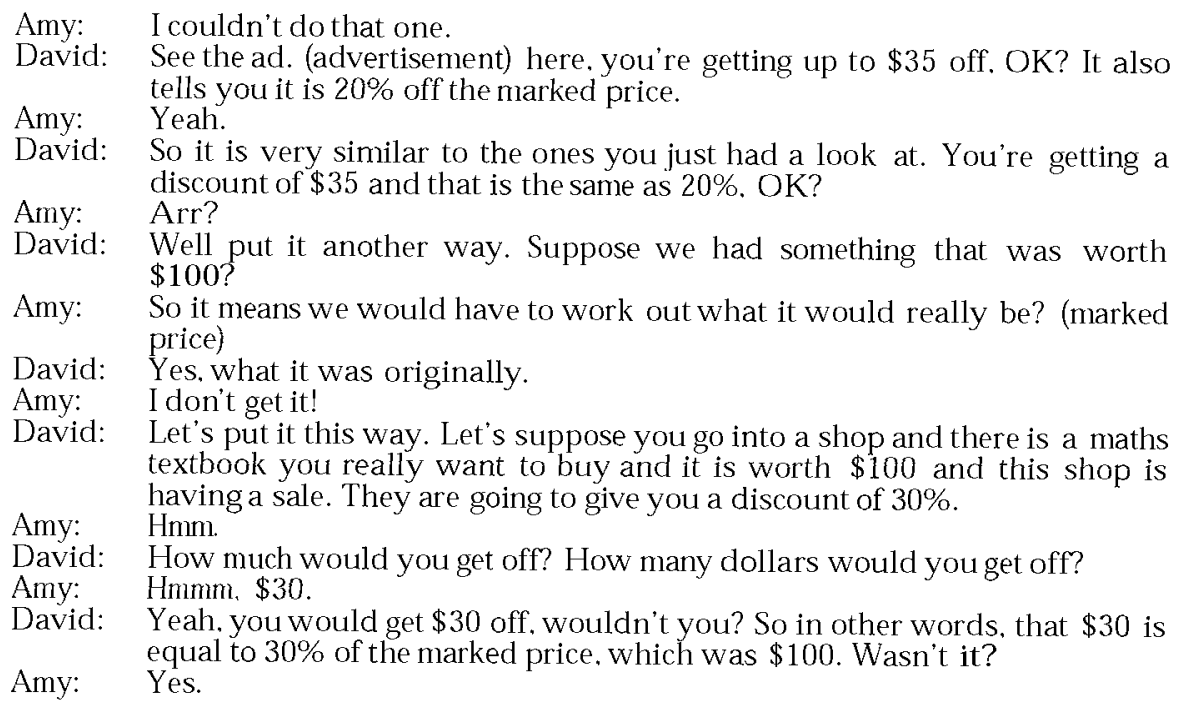

David's questions to Amy were explicit in trying to lead her to an understanding of the concepts. In doing this, he increasingly simplified the task and gradually removed the cognitive content from the problem consistent with the Topaze effect (Brousseau, 1984). In the example, it was David who took charge of the main part of the work. Later in this discourse he had even "worked out the rule" and directed Amy to follow his model. In his careful leading of Amy through simple steps, David was implementing his educational goals for less able students; that is, he tried to lead these students to understanding, but if this did not succeed he supplied models for them to imitate.

Like Eva, David's questioning emptied the mathematical activity of most of the cognitive challenge. However, Eva's show and tell questioning was directed at the whole class. In contrast, David's questioning was usually tailored to individual students. However, both the show and tell of Eva and the questioning of David focused on helping the students to do instrumental mathematics. When David's leading of students by careful questioning and explanations failed he showed students how to preform the procedures.

Because his focus was on explaining, David had different goals and strategies for more able students. For example, he did not start lessons to able students with mental arithmetic questions as he always did for less able students. As he explained:

Oh! It's an academically much brighter class. And I don't think they need to practise their mental arithmetic as such. They're bright kids and they focus pretty quickly on what's going on. So that is mostly for the junior grades. particularly those that are a bit slower.

Observations of David's teaching of his more able Year 11 Mathematics B class illustrated subtle differences in his pedagogy from that used with less able students. This is illustrated in the dialogue below. This is from a lesson in statistics to a class of 26 students, who were seated in four groups. It was the 
second in a sequence of lessons, and to start the lesson David had written on the white board:

8A:- 1. 2. 98, 99:

8B:- $48,49,51,52$.

He explained that these numbers represented the examination results of two classes and that the headmaster wanted to know the average mark for each class. The students calculated the average, which was 50 for both classes. David then began to focus the class's attention onto other aspects of the two classes with questions:

David: What sort of conclusion do you think the headmaster would draw about the two classes?

Students: They're both the same.

David: They're both the same. They're both the same types of classes. And yet, if you look at the results that l've there. for those two classes. I think you'd agree with me that they aren't the same types of classes. How would you describe Class $8 \mathrm{~B}$ ?

Student: All similar.

David: Yeah. they're all of a fairly similar standard. aren't they? OK? Anything else you could say about them? They're all pretty much middle of the range students aren't they? Nobody particularly bright there but nobody really weak either. OK? They're a pretty average lot of students, I suppose. 8A if you had to put some words on that class to describe them. How would you describe those students (lower marks in 8B)? Dumb? We've got the two extremes haven't we? OK? We've got a couple of genius at the top and a couple at the far end of the scale that haven't got a clue what's going on with their mathematics. So. when the headmaster says how are those classes going in Year 8, and if we just tell him an average mark. it's really quite misleading, isn't it, because it doesn't tell us much about how the classes in general are going because there's such a wide range of students in each class. Apart from giving all the individual marks themselves, if I just had to give some summary results. is there anything else that I could give, apart from the mean that might help this, convey what sort of students we've got in these classes?

Student: Median?

David: Alright, well what's the median for Class 8A? Well. there's two middle numbers, isn't there? What do we do when there's an even number of scores, there?

Student: Add the middle ones.

Dialogue of this nature continued for much of the class as David attempted to show his students the relevance and procedures associated with the median, range, and inter-quartile range. In the latter part of the lesson, students worked on problems contained in a textbook. Some students chose to work cooperatively and this was allowed. David had described the class as academically bright and there was evidence that he expected them to understand the concepts behind the procedures; that is, with more able students, the explanations of concepts were more detailed as they focused on why as well as how, and he appeared to expect these students to take greater cognitive steps.

David justified his teaching practices in relation to his perception that the curriculum was crowded. David was familiar with the investigative texts and understood the teaching approach they supported. David explained that one of the main reasons why he used his explain pedagogy rather than investigative approaches found in these texts was that:

I think it is the speed at which you can get through the work. I guess one of the 
overriding considerations are that you get through the work program ... (after all) you have only so many lessons.

\section{Summary and Relations to Other Explain Teachers}

Two other teachers Peter and Kurt (see Table 1) adopted strategies similar to David in their teaching of able students and used show and tell approaches with less able students. For them, the explain teaching approaches appeared to work on the assumption that student misinterpretation could be reduced if the teachers were particularly skilful in explaining and questioning. But as demonstrated by David in his teaching of statistics, a very good knowledge of the content was necessary. As has been noted (e.g., Crawford, 1996) teachers need to have a deep relational understanding of mathematical concepts in order to construct logical explanations. In this study, all the teachers who used predominantly explain approaches in their teaching were very experienced and mathematically knowledgeable. They all held positions of responsibility within their schools. They tended not to rely upon a textbook as the main source of authority and resource for classroom activities; they were able, and preferred, to construct their own explanations.

As for show and tell, explain teaching approaches were teacher-centred. This is to be expected since, as Peter said, "The knowledge is coming from me." The approach also exhibited the following behaviours:

- careful explanation of the logic underlying rules, step by step "Topaze" style questioning, construction of personal explanations and activities (rather than relying on the textbooks), some use of modelling activities, and allowing peer tutoring during the book work phase of lessons for more able students; and

- reversion to show and tell behaviour for less able students.

\section{Findings for the Investigative Teacher}

Jan was a 49-year-old female teacher with 25 years of secondary teaching experience. She was the chairperson of a zone moderation panel and had a very thorough knowledge of the senior syllabus. Jan acted as Head of Department when the incumbent was elsewhere. She taught both junior and senior mathematics including Mathematics B.

Jan had two distinct sets of goals for able and less able students. She explained "The kids that are not going to university, you just teach them enough so that they can get through their examinations and that is it." She stated that she taught able students "conceptually so that they can understand." She used different teaching strategies in attempting to achieve these goals, but favoured investigative activities and students working in groups to construct mathematical meaning when teaching new material.

The following description of a Year 9 lesson on quadrilaterals illustrates her investigative approach. It was taught to 31 students seated in groups of three or four. Jan started the lesson with quick questions of a computational nature like "eight minus sixteen" and "one third of six." The students worked individually on 
these tasks and wrote their answers in their exercise book. She explained each answer at the end of the test and accompanied the explanation with models of procedure on the white board. She stated later to the researcher that one reason she used questions at the beginning of the lesson was to "kick start the lesson."

The main part of the lesson involved investigating the features of quadrilaterals including parallelograms. She began this activity in the manner described below:

Right, quadrilaterals, quad Q.U.A.D, four babies, quads. Lateral refers to the number of sides. OK. Underneath I want you to make a list of as many special ones as you can without talking to any one. Don't draw them for the moment just make a list. Has any one got five? Has any one got three or four? OK. Juliet would you like to read yours out.

The students then offered their quadrilaterals At this stage, the pedagogy shifted from one that focused upon introducing the content to an alternative investigative model as illustrated by the introduction below:

What is special about each of these? Draw me a sketch of each one. Yes, you can draw. Think about what's special about each one. Then label them please. Any sides that are equal, any angles that are right angles, any sides that are parallel-mark them on your diagram.

During this process, students engaged in considerable discussion with their peers. Jan's comment on this was:

I honestly think that kids need to talk to each other. Because I think they learn from feeding off their ideas and talking to other people and putting in a bit and coming back. You know, if I sit in an isolated room by myself and try to do something, I'm really limited by what I've got up here (pointing to head).

This description indicated that Jan believed that doing mathematics was a social activity and was supported by her responses on the survey.

Later in the lessons, the students were asked to trace trapeziums into their books, draw in diagonals and measure the bisected lengths of each diagonal; she instructed them:

You have to do it for the two diagonals for each one. And write down the ratio. Right. obviously we're looking for a pattern. See if you can find a pattern between those? ... OK, take your ruler and draw in the diagonals and measure them. And get your calculator and use it.

In giving the instructions, Jan provided cognitive scaffolding and illustrated the integrated use of calculators to perform the ratio computations. After five more minutes of this activity, the following discussion occurred between Jan and a female student.

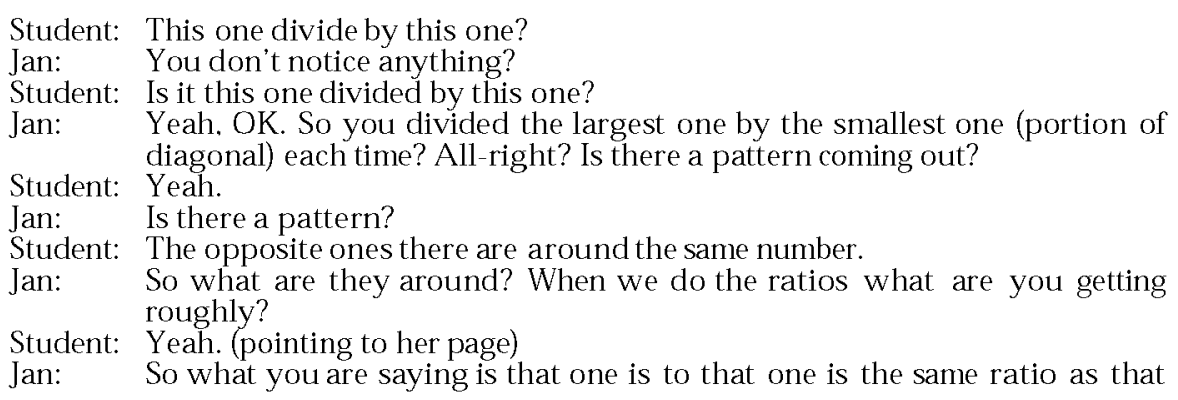


Student: Yeah.

The latter part of this dialogue illustrates Jan's tendency to increasingly take the responsibility for students' thinking if they experienced difficulty. Jan's acceptance, even encouragement, of approximation, and her persistent questioning ("Is there a pattern?") are consistent with an investigative approach to mathematics. Although Jan led the students with structural and procedural hints and, in the case above, articulated the idea that a constant ratio existed, she did not give the students the rule. Similar discussions occurred with other groups. At the end of the lesson, Jan summarised their work and made the conclusion for the class.

It may be argued that Jan's conclusion of the lesson undermined the opportunity for some of the students to construct their own conclusions. However, Jan allowed the students to invest 30 minutes to find a relationship that she could have explained on the black board in much less time. This is strong evidence that she was prepared to teach in an investigative way. This tended to mainly occur at the beginning of new work. Observations indicated that when Jan used investigative approaches to teach a mathematics topic, she employed more direct strategies, such as explain or show and tell, if students did not grasp the ideas in the allocated time:

$$
\begin{aligned}
& \text { Jan: What don't you know how to do? What's the gradient of the tangent at the } \\
& \text { point where } x \text { is equal to three? Any tangent? A tangent? When } x \text { equals } \\
& \text { three on the curve, what's the gradient of the tangent? } \\
& \text { Joanna: I don't know. }
\end{aligned}
$$

This dialogue and the subsequent observations supported Jan's statement to the researcher that she was "more directed in her teaching" for slower students.

Jan used similar teaching techniques with both the Year 9 students and the top group of Year 12 Mathematics B students who were working from an investigative resource. The researcher suggested to Jan that she adopted explain and show and tell teaching strategies when students failed to demonstrate understanding and that she realised that this might lead to less student conceptualisation but at least students would be helped in passing the examinations. Jan responded with a laugh, then said "I don't like the last bit, but yes it is true. That is how I feel even if I don't like it. That is a reality." This acceptance of the researcher's assertions reflects the multitude of pressures that are placed upon teachers. Jan tried to give students the opportunity to construct understanding. However, if this did not happen in the allotted time, she 
emphasised procedure.

\section{Summary and Relations to Other Investigative Teachers}

Two other teachers in this study, Simon and Mary, exhibited investigative approaches that were similar to Jan for more able students (but not for the less able). When interviewed, they spoke, like Jan, in terms of the greater importance of understanding and thinking over procedural skill.

Jan, Simon, and Mary all appeared to dislike having students conclude a task and remain doubtful of the meaning of the mathematics under study at the conclusion of a lesson. At the end of teaching sequences, they managed class discussions where inadequacies in student thinking were analysed and explanations consistent with accepted mathematical knowledge were articulated. However, if students did not come to construct understandings that were consistent with the shared meanings of the discipline before the lesson was due to end, these teachers adopted explain teaching behaviours. If students still struggled to understand they adopted show and tell strategies. That is, they gave recognition to the time-saving advantages of these approaches to teaching. In this way, the three teachers lowered their expectations for student understanding from conceptual to calculational. The teachers explained that they did this to ensure that students' "needs were been catered for" and that students "would be able to, at least, pass the semester examinations."

In summary, the behaviour exhibited by the investigative teachers in this study encouraged students to explore mathematical phenomena using the stimulus materials that they supplied. However, if students did not demonstrate mathematical understanding, they provided structural support in the form of guiding questions and, in some cases, this emptied the activity of cognitive challenge. Overall, the following behaviours were demonstrated by investigative teachers: using structural or scaffolding hints to guide students, using questions to develop meaning and to search for patterns and not just to maintain discipline, using a long wait time after questions, extensively using activity based problems (that often included the manipulation of materials), confronting students with the paucity of their knowledge, requiring students to justify their answers and to report their progress on tasks, using "Topaze like" leading questions some of the time, and using drill type questions for homework.

\section{Discussion}

In this study, the focus has been upon the Queensland Senior Mathematics Syllabus for Mathematics B. This syllabus is representative of reform syllabi that recommend an investigative approach to teaching mathematics. It has been implemented in the schools for over five years.

As Table 1 shows, all but two of the nine teachers observed had essentially calculational goals for less able students, and all had conceptual goals for more able students, while eight of the teachers stated that they mostly used show and tell approaches with less able students but differed in their approaches for the more able. It also indicates that the teachers felt that they were catering for the students' needs by doing this, and it is argued that teachers' interpretations of 
the syllabus provided a rationale for this.

For the less able, the argument is fairly straightforward. The teachers were familiar with the syllabus documents, knew that the students (and their parents) wanted passing grades, and realised that students did not need to demonstrate the deep conceptual understandings required in solving unfamiliar application questions in order to pass. Thus, since mathematical procedures can often be completed without conceptual understanding, the syllabus encouraged teachers to adopt limited goals for less able students. Other authors have noted that the routine application of procedure does not necessarily reflect conceptual understanding (e.g., Gregg, 1995; Neyland, 1996).

For the more able students, the analysis is more complex. All the teachers claimed to have conceptual goals for more able students and were concerned as to how they could teach these students to pass on the unfamiliar application assessment items where conceptual understanding was necessary. However, there were three different approaches used to achieve this. A first group of teachers universally adopted a show and tell approach, demonstrating a limited collection of teaching behaviours. A second group of teachers used the explain pedagogy where conceptualisation was a major goal and show and tell approaches otherwise, particularly to revise work, when they felt pressured by time constraints, or concluded that the understandings were beyond the students at this time. A third group used the most varied approaches to teaching the more able. They used investigative approaches to teach new conceptual work, and show and tell and explain approaches to revise concepts. They articulated a greater conviction that investigative learning activities were appropriate for developing student conceptualisation. Although they stated that getting students to pass examinations was important, this seemed not to dominate their rationale for adopting a particular pedagogy as much as the teachers who were restricted to the more teacher-centred teaching show and tell and explain behaviours. In fact, although they sometimes felt constrained by assessment and were uncomfortable with its dominant influence, they persisted with investigative approaches for more able students.

There appeared to be two possible reasons for not using investigative approaches, the pedagogy most in tune with unfamiliar application assessment items. The first reason seemed to be their belief that such approaches were "too slow" as most of the teachers struggled to complete the mathematical content recommended by the syllabus and claimed that this limited their choice of teaching strategy. Interestingly, although the crowded curriculum was important in influencing teachers' pedagogy, it was found not to be a critical factor for some teachers.

The second reason appeared to be that the three teachers who favoured investigative approaches to teaching mathematics were, or had been, Heads of Departments and thus had an in-depth understanding of the intentions of the Senior Syllabus and more experience teaching mathematics. Their teaching behaviour seemed to better reflect the intentions of the senior syllabus. This finding supports that of Perry et al. (1999) who found that curriculum leaders in schools were more inclined to have more child-centred beliefs about mathematics teaching than ordinary classroom teachers. However, it has to be taken into 
account that two of the remaining teachers were also HODs and the rest were very experienced senior teachers, including Advanced Skill Teachers (recognised as being highly skilled).

Only three teachers exhibited investigative approaches and all but one of the teachers tended to maintain teaching approaches more closely aligned to "direct instruction" for less able mathematics students. This is of concern. It indicates that the recommendations of the syllabus authors have not been universally enacted even among senior teachers. The majority of the teachers in this study had not adopted the investigative teaching approaches recommended by Australian educational bodies (AAMT, 1996: AEC, 1990) and the State syllabus documents (BSSSS, 1992; QSCC, 2000), and reflected in constructivist theories (Cobb, Yackel, \& Wood, 1992). This supports previous findings that many teachers have traditional approaches that are well entrenched (Crawford, 1996; Gregg, 1995: McDonald \& Ingvarson, 1995; Perry et al., 1999; Senger, 1999), and the effect of the reform agenda will not be dramatic or quick (Perry et al., 1999). However, the evidence from this study differs from Perry et al. (1999) in that the teachers in their study worked under a Syllabus that stated "the Board does not, however, either stipulate or evaluate specific teaching methods" (Board of Studies NSW, 1997, p. 7). In contrast the Queensland Syllabus has been more explicit in encouraging teachers to adopt reform approaches to teaching mathematics.

However, taking a different perspective, it could be considered encouraging that three of the nine teachers had adopted investigative approaches to teaching mathematics at least with able students. This supports the findings of Clarke (1999, p. 21) that over time teachers can become comfortable with "resisting the temptation to tell."

\section{Conclusions}

While most of the teachers in this study stated that they agreed with the principles behind syllabuses based upon constructivist learning theory (at least for able students), most teachers found it difficult to implement these strategies in the classroom. Their articulated reasons for not doing so related in part to their perceptions of the assessment criteria. A number of teachers stated that they were fulfilling their duties to both students and parents by getting them to pass examinations that could be passed with little need to demonstrate underlying concepts.

The implications of this study for investigative curriculum writers are that assessment criteria ought not to contain such a "loophole." In particular, all students ought to be required to demonstrate conceptual understanding by applying mathematics concepts in unfamiliar situations. Clear reasons why investigation is the best approach in the rationale of the syllabus, descriptions of how investigation can be enacted in the main body, and models of appropriate investigatory teaching activities, assessment criteria, and instruments in appendices, would seem to be advantageous. So also would be a comprehensive programme of professional development to accompany the syllabus. It was evident that some of the experienced teachers in this study did not have a clear 
mental image of alternative pedagogies to show and tell and explain, nor did they have a varied repertoire of teaching strategies to meet their calculational and conceptual goals. Professional development needs to address teachers' mental images and beliefs, recognise the calculational-conceptual distinction, and link goals to pedagogy.

In addition, the study indicates that further research needs to be done to determine the nature of the relationships between teachers' interpretations of syllabus documents, their perceptions of students' abilities, and how this impacts upon their teaching practice. It may be that changing the syllabus documents, including assessment criteria, so that conceptualisation is a prerequisite of passing, might bring about changes in teaching approaches of students classified as less mathematically able. The idea that teachers' deep values (the good of the child) and subsequent practices can be modified by changing teachers' instrumental beliefs (what constitutes good mathematics teaching) has been noted previously (Senger, 1999).

Further study also needs to determine the nature of professional development that could facilitate such a change in teachers' goals and approaches, in particular, assessment guidelines in influencing teacher change. Failure to take into account how teachers interpret and enact a reform syllabus ignores the welldocumented conservative nature of mathematics teaching in terms of embracing pedagogical reform (Cuban, 1984; Gregg, 1995). Thus, many students are likely to predominantly experience "practice and explain instruction that has failed to foster mathematical achievement" (Lo, Wheatley, \& Smith, 1994, p. 30). It should be noted that other authors have argued that careful explanation (with accompanied worked examples) can "be highly effective at facilitating learning across a wide range of mathematically based content" since the degree of cognitive load is relatively small (Cooper, 1998, p. 18). Perhaps the argument in relation to investigative teaching practices is not so much about understanding mathematics but the degree to which the different teaching methods foster generic problem solving skills and autonomous learning behaviours?

\section{References}

Allen. F. B. (1998). Repairing school mathematics in the US. Retrieved January 7, 1999, from the Mathematically Correct Web site: http://mathematicallycorrect.com/report.htm

Anderson. P. (1994). Years 1-7 mathematics syllabus support document: A content core for a school-based program in Queensland primary schools. Brisbane: Queensland Department of Education.

Atweh. B.. \& Cooper. T. (1995). The construction of gender, social class and mathematics in the classroom. Educational Studies in Mathematics, 28, 293-310.

Australian Association of Mathematics Teachers. (1996). Statement on the use of calculators and computers for mathematics in Australian schools. Adelaide: Australian Association of Mathematics Teachers Inc.

Australian Education Council (AEC). (1990). A national statement on mathematics for Australian schools. Melbourne: Curriculum Corporation.

Barnes. M. (1991). Investigating change: An introduction to calculus for Australian schools. Melbourne: Curriculum Corporation.

Barnes, M.. Clarke. D.. \& Stephens, M. (1996). The impact of external assessment on teaching practice: Constraints on change in the classroom. In P. Clarkson (Ed.). Technology in mathematics education (Proceedings of the $18^{\mathrm{th}}$ annual conference of the Mathematics Education Research Group of Australasia. pp. 65-71). Melbourne: MERGA. 
Board of Senior Secondary School Studies (BSSSS). (1992). Senior Syllabus in Mathematics B. Brisbane: Author.

Board of Studies NSW. (1997). Mathematics 2/3 Unit Years 11-12. Sydney: Author.

Brousseau. G. (1984). The crucial role of the didactical contract in the analysis and construction of situations in teaching and learning mathematics. In H.-G. Steiner (Ed.), Theory of Mathematics Education (pp. 110-119). Occasional Paper 54. Bielefeld. Geremany: University of Bielefeld. Institut fur Didaktik der Mathematik.

Carrol. W. M. (1997). Results of third-grade students in a reform curriculum on the Illinios State Mathematics Test. Journal for Research in Mathematics Education, 28(2), 237-242.

Clarke, D. M. (1999). Classroom reform five years down the track: The experiences of two teachers. Mathematics Education Research Journal, 11(1), 4-24.

Cobb. P. (1988). The tension between theories of learning and instruction in mathematics education. Educational Psychologist, $23(2)$. 87-101.

Cobb. P. (1989). Experiential. cognitive and anthropological perspective in mathematics education. For the Learning of Mathematics, 9(2). 32-42.

Cobb.P. Yackel. E.. \& Wood. T. (1992). A constructivist alternative to the representational view of mind in mathematics education. Journal for Research in Mathematics Education, $23(1), 2-33$

Cooper. G. (1998). Research into cognitive load theory and instructional design at UNSW. Retrieved August 18. 2001. from http://www.arts.unsw.edu.au/education/ CLT_NET_Aug_97.HTML

Crawford, K. (1996). Vygotskian approaches in human development in the information era. Educational Studies in Mathematics, 31(1). 63-93.

Cuban. L. (1984). How teachers taught: Constancy and change in American classrooms, 1890 1980. New York: Longman.

Curriculum Council. (1998). Curriculum framework for kindergarten to Year 12 education in Western Australia. Osborne Park. WA: Author.

Denzin. N.. \& Lincoln. Y. (1994). Part V: The art of interpretation. evaluation, and presentation. In N. K. Denzin, \& Y. S. Lincoln (Eds.), Handbook of qualitative research (pp. 479-483). Thousand Oaks, CA: Sage.

Ernest, P. (1989). What's the use of LOGO? In P. Ernest (Ed.), Mathematics teaching: "The state of the art" (pp. 33-44). London: Falmer.

Ernest. P. (1991). The philosophy of mathematics education. London: Falmer.

Ernest, P. (1996). The nature of mathematics and teaching. Retrieved November 24, 1998, from http://www.ex.ac.uk/_PErnest/pome/pompart7.htm

Fontana. A., \& Frey. J. H. (1994). Interviewing the art of science. In N. K. Denzin, \& Y. Lincoln (Eds.). Handbook of qualitative research (pp. 361-376). Thousand Oaks, CA: Sage.

Gregg. J. (1995). The tensions and contradictions of the school mathematics tradition. Journal for Research in Mathematics Education, 26(5), 442-466.

Guba, E.. \& Lincoln. Y. (1989). Fourth generation evaluation. London: Sage.

Kagan. D. M. (1992). Implications of research on teacher belief. Educational Psychologist, $27(1), 65-90$

Kuhs, T., \& Ball. D. (1986). Approaches to teaching mathematics: Mapping the domains of knowledge, skills, and dispositions. East Lansing. MI: Michigan State University. Centre on Teacher Education.

Lesh. R.. \& Kelly, A. E. (1997). Teachers' evolving conceptions of one-to-one tutoring: A threetiered teaching experiment. Journal for Research in Mathematics Education, 28(4). 398427

Lo, J.. Wheatley. G.. \& Smith. A. (1994). The participation, beliefs and development of arithmetic meaning of a third-grade student in mathematics class discussions. Journal for Research in Mathematics Education, 25(1). 30-49.

Lowe. I.. Johnston. J.. Kissane, B., \& Willis. B. (1993). Access to algebra. Melbourne: Curriculum Corporation.

Maykut. P.. \& Morehouse, R. (1994). Beginning qualitative research: A philosophical and practical guide. London: Falmer.

McDonald. H.. \& Ingvarson, L. (1995). Free at last? Teachers, computers and independent learning. Paper presented at the annual meeting of the American Educational Research Association. San Francisco, CA. (ERIC Document Reproduction Service No. ED 389 278).

McRobbie, C.. \& Tobin. K. (1995). Restraints to reform: The congruence of teacher and student actions in a chemistry classroom. Journal of Research in Science Teaching, 32(4). 373-385.

National Research Council. Mathematical Sciences Education Board. (1989). Everybody counts: A report to the nation on the future of mathematics education. Washington, DC: National Academy Press. 
National Council of Teachers of Mathematics. (2000). Principles and standards for school mathematics: A vision for school mathematics. Retrieved May 23, 2001, from NCTM Web site: http://standards.nctm.org/document/chapter1/index.htm

Neyland, J. (1996). Teachers' knowledge: The starting point for a critical analysis of mathematics teaching. Retrieved November 24, 1997, from http://www.ex.ac.uk/ $\sim$ PErnes/pome/pompart4htm

Perry, B., Howard. P.. \& Tracey. D. (1999). Head mathematics teachers' beliefs about the learning and teaching of mathematics. Mathematics Education Research Journal, 11(1), 3953.

Queensland School Curriculum Council. (2000). Draft syllabus P-10. Brisbane: Author.

Schwandt. T. (1994). Constructivism. interpretist approaches to human inquiry. In N. K. Denzin. \& Y. S. Lincoln (Eds.). Handbook of qualitative research (pp. 118-123). Thousand Oaks, CA: Sage.

Senger, E. S. (1999). Reflective reform in mathematics: The recursive nature of teacher change. Educational Studies in Mathematics, 37. 199-221.

Senior Secondary Assessment Board of South Australia. (2000). Mathematics 2. Stage 2 Detailed Syllabus Statement. Adelaide: Mathematics Board Field of Study.

Skemp. R. (1978). Relational understanding and instrumental understanding. Mathematics Teaching, 77, 20-26.

Stenhouse. L. (1990). Case study methods. In H. J. Walberg, \& G. D. Haertel (Eds.). The international encyclopedia of educational evaluation (pp. 644-649). Oxford, UK: Pergamon.

Tall, D. O., \& Thomas, M. O. J. (1991). Encouraging versatile thinking in algebra using the computer, Educational Studies in Mathematics. 22. 125-147.

Thompson. A.. Phillip. R.. Thompson. P.. \& Boyd. B. (1994). Calculational and conceptual orientations in teaching mathematics. In D. Aichele. \& A. Coxford (Eds.), Professional development for teachers of mathematics (pp. 79-92). Reston, VA: National Council of Teachers of Mathematics.

Vygotsky. L. S. (1987). The collected works of L. S. Vygotsky (Volume 1). New York: Plenum .

Wasley. B.. Manche, D., \& Winter. R. (1996). Mathematics Year 10 for Queensland. Melbourne: Oxford University Press.

\section{Authors}

Stephen Norton, School of Mathematics. Science and Technology Education. Queensland University of Technology. Kelvin Grove Q 4059. Email: <sj.norton@qut.edu.au>.

Campbell McRobbie, School of Mathematics. Science and Technology Education, Queensland University of Technology. Kelvin Grove Q 4059. Email: <c.mcrobbie@ qut.edu.au>.

Tom Cooper, School of Mathematics, Science and Technology Education, Queensland University of Technology, Kelvin Grove Q 4059. Email: <tj.cooper@qut.edu.au>. 